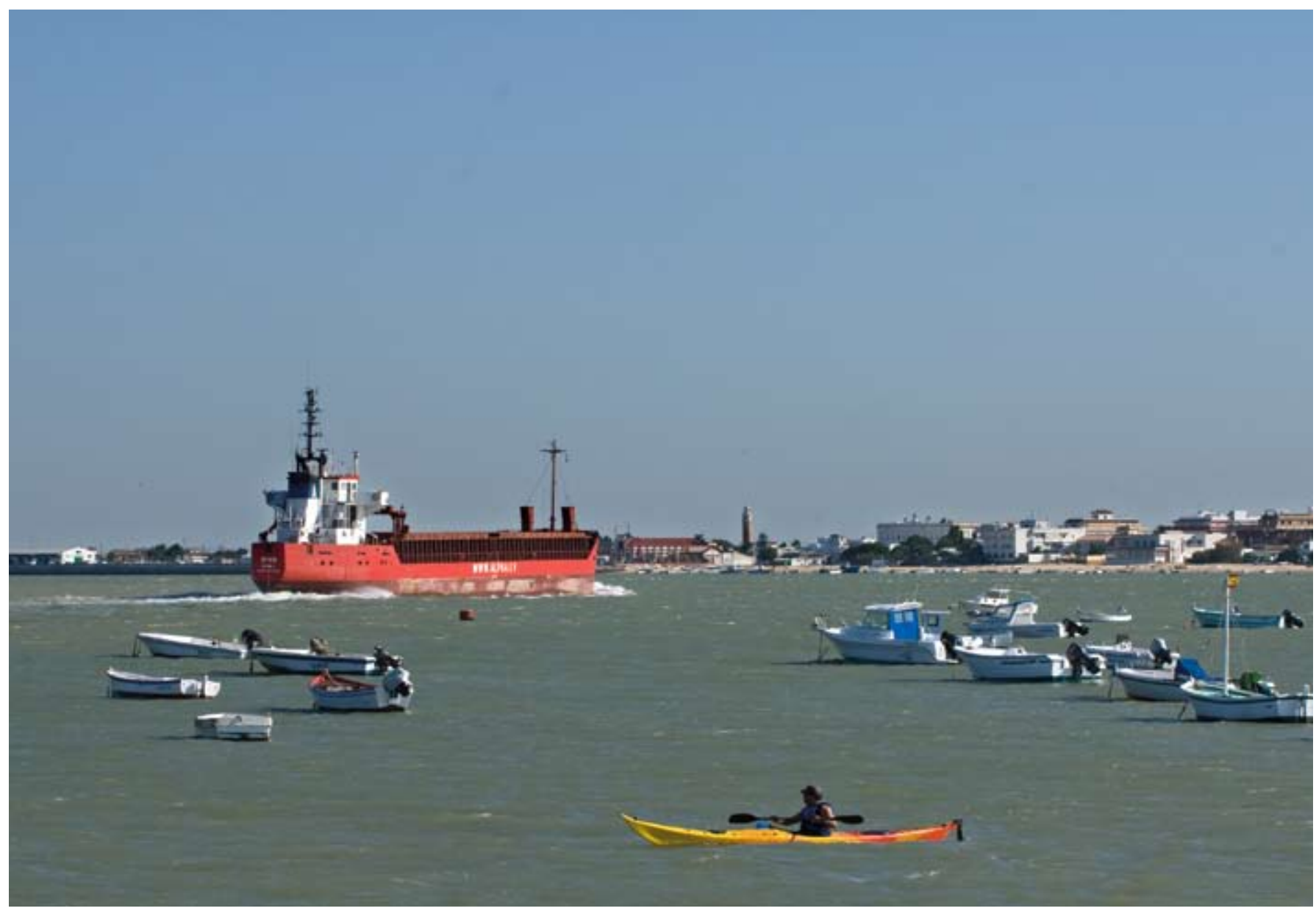

La desembocadura del Guadalquivir en el término de Sanlúcar de Barrameda conforma un paisaje único donde limitan las provincias de Cádiz y Huelva con el Parque Nacional de Doñana en la parte onubense. Foto: Juan Carlos Cazalla, IAPH

\title{
La desembocadura del Guadalquivir
}

Generada a partir de la aportación de sedimentos por parte del Guadalquivir y creada a raiz de la confluencia entre el mar y la desembocadura de un río, la mirada hacia la desembocadura del Guadalquivir como paisaje cultural implica hacer un recorrido por aquellos elementos y actividades culturales presentes a lo largo de su historia que han contribuido a la generación de este excepcional paisaje cultural.

Geográficamente este paisaje, que para unos es percibido como frontera y para otros como puente, pertenece, en su banda izquierda, a la localidad de Sanlúcar de Barrameda -provincia de Cádiz-, mientras que en su banda derecha -provincia de Huelva-, se localiza unos de los espacios naturales más importantes a nivel europeo, el Parque Nacional de Doñana, en este caso en la zona sur del municipio de Almonte. Se trata, por tanto, de un paisaje cultural generado a través de la presencia de un río y su desembocadura que, aunque legalmente pertenezcan a provincias distintas, no se pueden entender sin atender a los diferentes procesos geológicos que han configurado la zona y a las sucesivas actividades desarrolladas a lo largo de la historia de un río como el Guadalquivir, una arteria fundamental para la historia del territorio andaluz.
Y es que hablar del Guadalquivir implica hablar de un río a través de cuyas aguas nuestro territorio ha recibido la influencia de gentes que dejaron su impronta en el paisaje andaluz y forjaron nuestra identidad como pueblo. De esta forma, en sus oriIlas podemos admirar las huellas más visibles que dejaron romanos, árabes y conquistadores cristianos, claros exponentes de un sincretismo cultural que la población andaluza ha custodiado con orgullo.

El Guadalquivir ha sido también canal de comunicación entre América y Andalucia, puerta de entrada a Europa y vía de salida hacia el Nuevo Mundo. Por ello, no ha sido nunca para los andaluces una frontera, sino también un puente que ha permitido nuestro enriquecimiento cultural a través de la filosofía, las artes y las ciencias. Por ello, además de comunicarnos con el mundo, esta arteria fluvial y toda su cuenca hidrográfica han vertebrado nuestro territorio, conectando pueblos y ciudades y bañando sus orillas como testigo atento $y$ artífice activo de su historia.

En la zona de su desembocadura, todas las cuestiones mencionadas se sintetizan y hacen evidentes a través del ingente patrimonio cultural -tangible e intangible- y natural que ha llegado hasta nuestros dias: las factorías de salazón localizadas en la zona de la Algaida de Sanlúcar de Barrameda y en el Cerro del Trigo en el actual Parque Nacional de Doñana, la histórica explotación de las salinas en ambos márgenes; el desarrollo de técnicas especificas para la pesca cuya práctica derivó en la construcción de corrales marinos y la creación de zonas para el fondeo de barcos en la orilla sanluqueña de forma paralela a la configuración de barrios pesqueros, caso del de Bajo de Guía, que han llegado hasta nuestros dias como importantes referentes gastronómicos surpralocales. En la misma línea se deben resaltar la aparición y consolidación del Puerto de Bonanza y su lonja, y el desarrollo de unas prácticas gastronómicas construidas en torno a las materias primas de la desembocadura y los usos marineros. Todos estos elementos, actividades y procesos, forman parte de un paisaje cultural de honda raigambre histórica, donde ha tenido y tiene lugar una significativa fusión entre elementos culturales y naturales.

Isabel Durán

Centro de Documentación, IAPH 